\title{
Asymptomatic ST-segment changes in athletes with myocardial bridge: unremarkable or dangerous?
}

\author{
Massimo Bolognesi ${ }^{*}$ and Diletta Bolognesi ${ }^{2}$ \\ ${ }^{1}$ Sports Cardiology Medicine Center, Ausl della Romagna, Cesena, Italy \\ ${ }^{2} J u n i o r$ Doctor, Territorial Medicine, Ausl della Romagna, Cesena, Italy
}

\begin{abstract}
Coronary artery anomalies are a cause of sudden death in athletes in the absence of additional heart abnormalities. Understanding the pathophysiology is important in guiding management because variations in coronary anatomy are common. Myocardial bridging (intramural coronary artery) is a common congenital coronary anomaly that involves almost exclusively the left anterior descending coronary artery (LAD), and is regarded as a common anatomic variant rather than a congenital anomaly. It is clinically silent in the majority of cases. Asymptomatic athletes with positive exercise testing have a high probability of having a myocardial bridge. So the presence of ventricular repolarization abnormalities, such as ST segment depression, during stress tests meet clear indication to investigate by means of coronary computed tomography to rule out the presence of this anomaly. Here the authors describe a case of a middle-aged competitive athlete who presented a positive exercise test and was withdrawn from competition for the coexistence of a deep and long myocardial bridge at high risk of sudden death.
\end{abstract}

\section{Introduction}

Knowledge of physiology, normal and variant anatomy, and anomalies of coronary circulation is an increasingly vital component in managing congenital heart diseases. Importantly, coronary artery anomalies are a cause of sudden death in young athletes in the absence of additional heart abnormalities. Understanding the pathophysiology is important in guiding management because variations in coronary anatomy are common. Because of the considerable heterogeneity of coronary vasculature, what is considered atypical, abnormal, aberrant, anomalous, accessory, ectopic, incidental, variant, or significant is often unclear. Primary congenital coronary anomalies are anatomical variations of the origin, course and termination of coronary arteries, which are not associated with complex congenital heart disease. Coronary artery anomalies (CAAs) have been associated with numerous symptoms, such as angina, dyspnea on exertion, ventricular tachycardia and myocardial infarction [1,2]. The subject of CAAs is undergoing profound evolutionary changes related to the definition, morphogenesis, clinical presentation, diagnostic workup, prognosis, and treatment of these anomalies. In order to understand the clinical impact of CAAs, the key challenge is the refined and solid reasoning, for a particular type of CAA, of a mechanism capable of interference with the coronary artery's function, which is to provide adequate blood flow to the dependent myocardium [3]. Myocardial bridging (i.e. intramural coronary artery) is a common congenital coronary anomaly that involves almost exclusively the left anterior descending coronary artery (LAD) [4], and is regarded as a common anatomic variant rather than a congenital anomaly [5]. It is clinically silent in the majority of cases [6]. After hypertrophic cardiomyopathy, CAAs are considered to be the second major cause of death in young athletes $[7,8]$. Some authors prefer to categorize CAAs only as "major", "severe", "important", or "hemodynamically significant" anomalies versus "minor" ones [1], but what is important is their clinical significance. The focus of this article concerns the myocardial bridging in athletes and its relation with the eligibility for competitive sport. Coronary arteries that tunnel through the myocardium are seen in as many as $40 \%$ to $80 \%$ of cases on autopsy. However, functional myocardial bridging is less commonly observed on angiography $(0.5 \%$ to $16.0 \%)$ and can range from 4 to $80 \mathrm{~mm}$ in length $[9,10]$. Although myocardial bridges can be found in any epicardial artery, $67 \%$ to $98 \%$ occur in the left anterior descending coronary artery (LAD) $[11,12]$. Bridges have been described as superficial or deep on the basis of three observations: 1 ) the range from 0.3 to $28 \mathrm{~mm}$ in depth [11-13]; 2) anatomically they consist of either superficial myocardial fibers that traverse over the LAD or deep fibers that encircle the LAD [14]; and 3) bridges $>5 \mathrm{~mm}$ deep are less amenable to surgical myotomy [15]. It is therefore clear that the hemodynamic impact of myocardial bridging depends on the thickness and length of the bridge,the orientation of the bridge relative to myocardial fibers, and the presence of loose connective or adipose tissue around the bridged segment. Despite the fact that the clinical outcome of patients with intramural left anterior descending coronary artery has been considered benign by most physicians [9], the significance of a myocardial bridge versus myocardial ischemia remains controversial. Indeed, some case reports suggest that myocardial ischemia and myocardial infarction or sudden death can be caused by myocardial bridging [16]. The prevailing hypothesis supports that mechanisms by which myocardial bridging causes myocardial ischemia include compromised coronary blood flow, endothelial dysfunction, thrombus formation and a strong association with coronary vasospasm [17]. Here the authors explain how it is possible to assume, mainly in athletes, the presence of a myocardial bridge through the interpretation of electrocardiographic findings

Correspondence to: Massimo Bolognesi, Sports Cardiology Medicine Center, Ausl della Romagna - Cesena, Italy, Tel: +390547645074; E-mail: massbolo1@tin.it

Key words: coronary artery anomalies, myocardial bridge, exercise stress test, athletes, coronary computed tomography angiogram

Received: February 15, 2015; Accepted: March 08, 2015; Published: March 12, 2015 
such as theventricular repolarization abnormalities, i.e. ST segment depression, recorded during exercise ECG stress testing. The authors describe with a case study the aspects of the pathway which followed the detection of an inducible myocardial ischemia during an exercise stress test in an asymptomatic athlete.

Finally, the authors describe the anatomical features of myocardial bridging that materialize the risk of sudden death in asymptomatic athletes with ECG signs of inducible ischemia on stress testing.

\section{Our experience}

A 44-year-old male competitive amateur cyclist came to our center to undergo a sports preparticipation screening. His personal history was negative for cardiovascular disease or any cardiac symptoms. He was nota smoker and he denied use of drugs or other medicaments. His family history was negative for ischemic heart disease or premature sudden death. The athlete was in good shape and excellent athletic condition; weight was $70 \mathrm{Kg}$, height $178 \mathrm{~cm}$; with a BSA of 1,87 $\mathrm{m}^{2}$. Physical examination was unremarkable and blood pressure was $120 / 70 \mathrm{mmHg}$. The 12-lead resting ECG showed normal sinus rhythm with normal QRS axis; QTc was within normal limits and the ventricular repolarization pattern was normal (Figure 1). The exercise stress testing, starting from 50 watt for 3 minutes, showed earlyJ-point depression (Figure 2) with ST segment downsloping and negative $\mathrm{T}$ waves in precordial leads from V4 to V6. During exercise stress a progressive depression of the J-point with ST-segment downsloping (Figure 3 ) from the same leads was observed. The ST segments changes

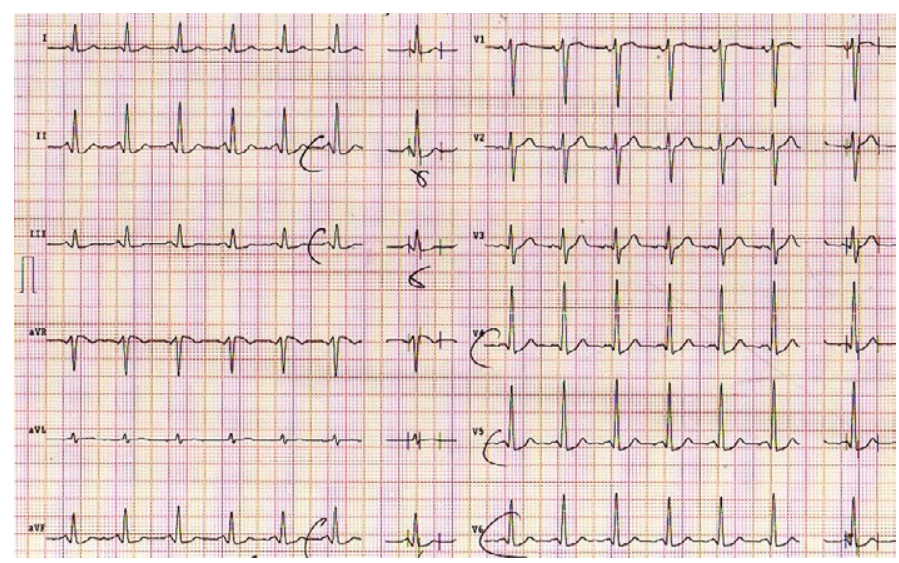

Figure 1. Resting ECG shows normal ventricular repolarization.

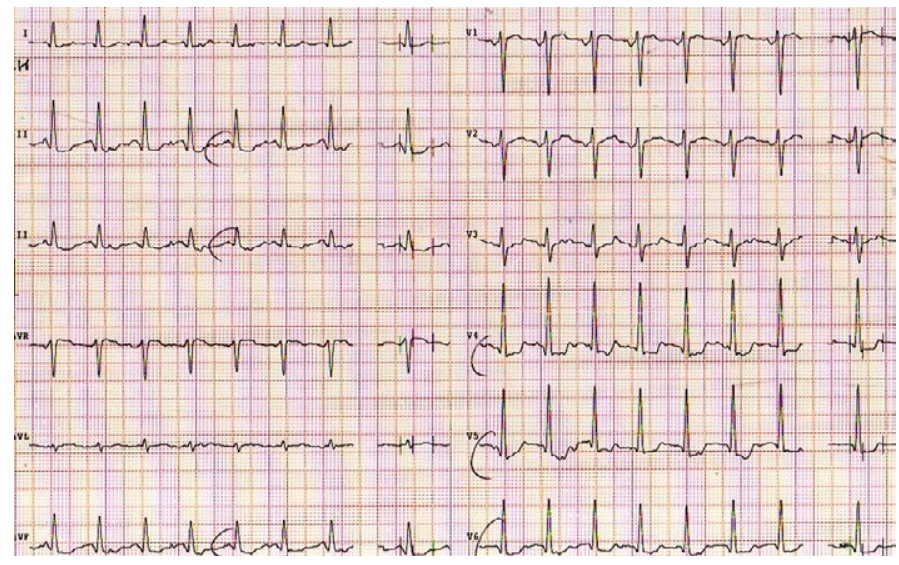

Figure 2. ECG during warm up exercise stress test with early ST-segment depression.

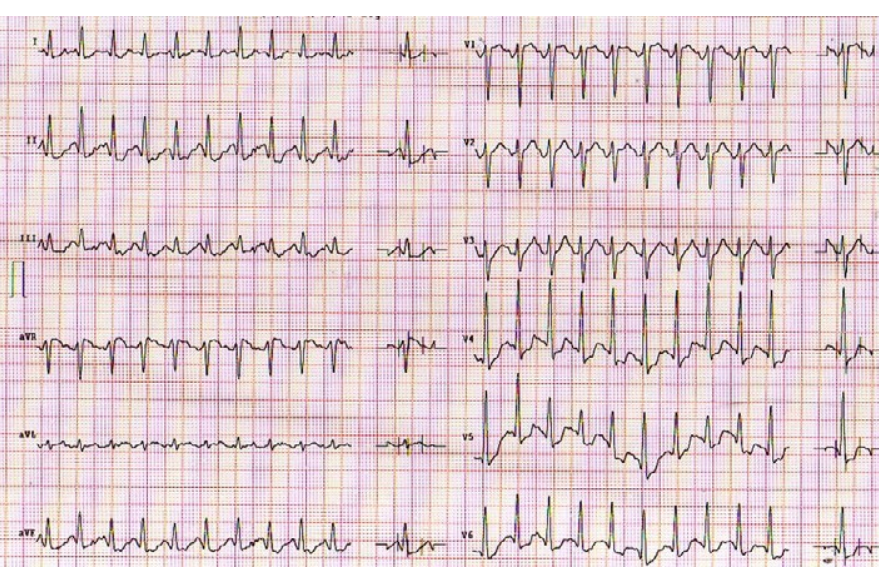

Figure 3. ECG peak exercise stress test with marked ST-segment depression.

\section{Depth Intramural Descending Coronary Artery}
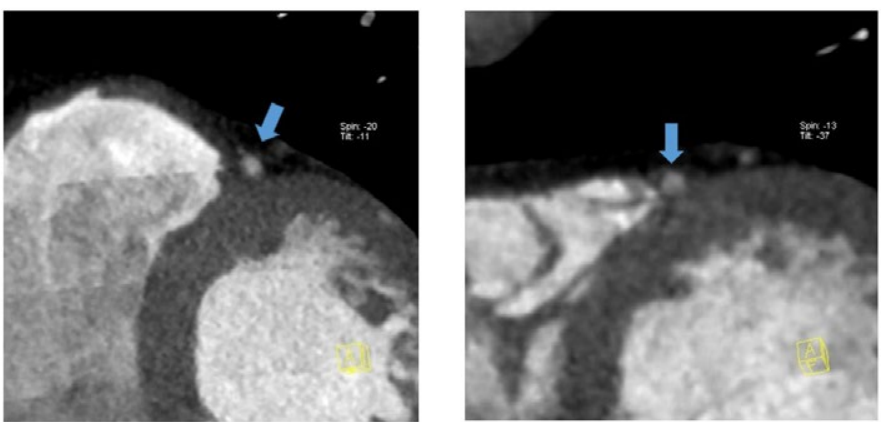

Figure 4. Intramyocardial course of the left anterior descending coronary artery (see blue arrows) (Courtesy of Prof. Filippo Cademartiri).

persisted in the recovery period. The athlete, however, remained completely asymptomatic. Echocardiographic examination showed mild left ventricular hypertrophy with normal systolic function. A subsequent coronary computed tomographic angiogram showed a long $(11 \mathrm{~cm})$ and deep anterior interventricular artery intramural course (myocardial bridge) (Figures 4 and 5), with a proximal atherosclerotic plaque and narrowing of less than $50 \%$ of the coronary lumen. The athlete was withdrawn from competitions.

\section{Discussion}

The literature reports a study by Corrado et al. who published an ESC consensus document on the screening of athletes for competitive sports [18]. It is not unusual for athletes to exhibit an "abnormal" ECG due to the effect of exercise training on the anatomy and autonomic control of the heart. Most of the changes are present in athletes who participate in endurance events; they are more common in males than in females, and in individuals of African descent [19]. Up to $80 \%$ of highly trained athletes show some evidence of ECG changes. Most of which can be considered physiologic adaptations to exercise training and do not necessarily indicate any pathology or concern. However, it is important to understand which ECG abnormalities may be physiologic and which are likely to be pathologic. The clinical significance of ST segment anomalies occurring during exercise test in asymptomatic individuals, particularly athletes, has always been debated, although numerous studies [20] have shown that an ischemic ST-segment response to exercise is a powerful harbinger for future coronary events (i.e., angina pectoris, myocardial infarction, or sudden cardiac 
Length Myocardial Muscle Bridge
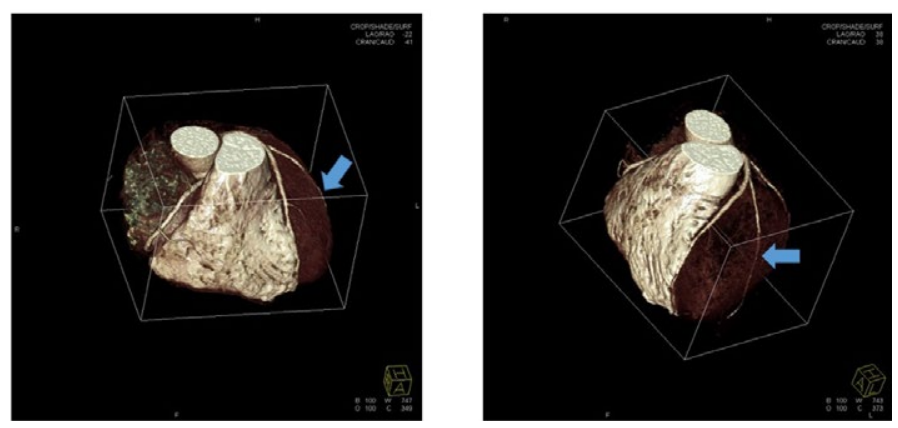

Figure 5. CCTA shows the length of myocardial muscular bridge (see blue arrows) (Courtesy of Prof. Filippo Cademartiri).

death) in apparently healthy populations [21]. Maron et al. stated that exercise ECG stress testing is the most frequently non-invasive test used to detect CAD in symptomatic and/or high risk subjects [22]. However, the predictive value of exercise testing for screening CAD in asymptomatic, low risk subjects is controversial, given the very low pretest probability of identifying the pathology [23].

Some data suggest a higher prevalence of silent ischemia in veteran athletes than in their sedentary counterparts [24,25], even though a high prevalence of false positive exercise tests among master endurance athletes has also been reported [26]. The Italian Society of Sports Cardiology recommends periodical cardiovascular evaluation, including an exercise test to exhaustion, for all subjects over 40 before granting them eligibility to participate in competitive sports [27]. Ventricular repolarization abnormalities during maximal exercise testing are usuallyelectrocardiographic findingsin patients with coronary artery disease, present in both symptomatic and asymptomatic patients. Individuals with ST segment depression during exercise testing, in the absence of symptoms, are often athletes undergoing sports preparticipation screening. The significance of these electrocardiographic abnormalities is unclear, often uncertain, and it is difficult for physicians to judge. In the common practice these alterations of ventricular repolarization in asymptomatic athletes are frequently considered false positive tests. The most striking abnormality found in anathlete of a case report was the significant ST-segment down sloping depression induced by exercise stress test, which was suggestive for silent ischemic heart disease. Considering that the athlete was relatively young and with no cardiovascular risk factors (i.e. low risk profile), the hypothesis believed to be the most probable was the presence of a congenital coronary artery anomaly, such as an abnormal origin or a intramural coronary artery (muscular bridge on IVA). Indeed, myocardial bridge anomaly was confirmed by CCTA.The COCIS 2009 [27] includes the myocardial bridging among the congenital abnormalities of the coronary circulation and states that this disease precludes suitability for competitive sports, as such athletes are at risk of sudden death, even in the absence of signs of inducible stress test ischemia.However, this cannot be considered an absolute dogma. In fact, the incidence of myocardial bridging in autopsies is very high, but this has not always been the cause of death.

Similarly, the presence of myocardial bridge is common in athletes, but only in few cases this anomaly can be deemed a risk of sudden death, because the majority of athletes compete in absolute tranquility even though they might have a myocardial bridge. The difference and challenge in sports medicine is then to precisely recognize the athletes with positive exercise test for inducible ischemia associated to myocardial bridge who requires disqualification from competitive sports. In essence: is the presence of inducible myocardial ischemia on stress testing with the coexistence of a myocardial bridging demonstrated by cardiac imaging tests sufficient to exclude an asymptomatic athlete from competition? Our data in agreement with literature [28] suggest the use of coronary CT angiography (CCTA) when athletes show repolarization anomalies during exercise and its recovery phase. Although the positive predictive value of a maximal exercise test in asymptomatic athletes appears lower than what observed in patients at high risk for coronary artery disease, about half of the athletes withequivocal or positive exercise test demonstrated some coronary abnormalities.Recently the Italian Sports Cardiology guidelines [29] recommend to disqualify athletes or issue temporary sports eligibility when a diagnostic doubt persists also after such tests.

The learning points of this article are as follows:

1) The clinical significance of inducible ischemia detected during exercise testing in asymptomatic athletes should be always well analyzed;

2) A relationship between abnormalities of ventricular repolarization and the presence of a myocardial bridge found at the coronary Tomography Computed angiogram may be suspected;

3) Coronary CT Angiography as modern cardiovascular imaging enhances our knowledge of the spectrum of the athlete's heart. Its role may expand from the assessment of athletes with suspected disease to being part of a comprehensive pre-participation screening in apparently healthy athletes.

\section{Conclusion}

Anomalies such as myocardial bridge should be regarded as an uneven diverse group of congenital disorders whose manifestations and pathophysiological mechanisms are highly variable.In order to be competent to detect and advise myocardial bridge carriers, especially in the context of sporting activities, sports cardiologists should undergo specific training with many years of ECG stress testing and have a specific knowledge on coronary artery diseases.

Here the authors have reached the conclusion that when electrocardiographic findings of inducible silent myocardial ischemia at low workload are present in healthy athletes, it is mandatory to perform a computed tomography coronary angiogram. The purpose of this test is to investigate the coexistence of a muscular bridge and its anatomic characteristics, i.e., length and depth of the intramural segment of the coronary artery, in an attempt to identify a high-risk characteristic. Such procedure could assist in the risk stratification of patients diagnosed with anomalous coronary artery. The authors hypothesize an association between the length and depth of the intramural coronary artery segment and the risk of sudden cardiac death. This paper should help physicians and sports cardiologist to keep in mind the clinical importance of requiring CCTA as second-level investigation for those athletes who show not only a positive, but also an equivocal exercise stress and not to considered it as a false positive test.

\section{References}

1. Angelini P (1992) Normal and anomalous coronary arteries in humans. In: Coronary Artery Anomalies: A Comprehensive Approach. Philadelphia: Lippincott Williams and Wilkins, 27-150.S

2. Bland E, White $\mathrm{P}$ (1933) Congenital anomalies of the coronary arteries: Report of an unusual case associated with cardiac hypertrophy. Am Heart $J$ 8: 787-801. 
3. Angelini P (2007) Coronary artery anomalies: an entity in search of an identity. Circulation 115: 1296-1305. [Crossref]

4. Ishii T, Asuwa N, Masuda S, Ishikawa Y (1998) The effects of a myocardial bridge on coronary atherosclerosis and ischaemia. J Pathol 185: 4-9. [Crossref]

5. Konen E, Goitein O, Di Segni E (2008) Myocardial bridging, a common anatomical variant rather than a congenital anomaly. Semin Ultrasound CT MR 29: 195-203. [Crossref]

6. Roberts WC (1986) Major anomalies of coronary arterial origin seen in adulthood. $\mathrm{Am}$ Heart $J$ 111: 941-963. [Crossref]

7. Van Camp SP, Bloor CM, Mueller FO, Cantu RC, Olson HG (1995) Nontraumatic sports death in high school and college athletes. Med Sci Sports Exerc 27: 641-647. [Crossref]

8. Eckart RE, Scoville SL, Campbell CL, Shry EA, Stajduhar KC, et al. (2004) Sudden death in young adults: a 25 -year review of autopsies in military recruits. Ann Intern Med 141: 829-834. [Crossref]

9. Möhlenkamp S, Hort W, Ge J, Erbel R (2002) Update on myocardial bridging. Circulation 106: 2616-2622. [Crossref]

10. Wu QY, Xu ZH (2007) Surgical treatment of myocardial bridging: report of 31 cases. Chin Med J (Engl) 120: 1689-1693. [Crossref]

11. Loukas M, Curry B, Bowers M, Louis RG Jr, Bartczak A, et al. (2006) The relationship of myocardial bridges to coronary artery dominance in the adult human heart. J Anat 209: 43-50. [Crossref]

12. Qian JY, Zhang F, Dong M, Ma JY, Ge L, et al. (2009) Prevalence and characteristics of myocardial bridging in coronary angiogram-data from consecutive 5525 patients. Chin Med J (Engl) 122: 632-635. [Crossref]

13. Wu QY, Xu ZH (2007) Surgical treatment of myocardial bridging: report of 31 cases. Chin Med J (Engl) 120: 1689-1693. [Crossref]

14. Ferreira AG Jr, Trotter SE, König B Jr, Décourt LV, Fox K, et al. (1991) Myocardial bridges: morphological and functional aspects. Br Heart J 66: 364-367. [Crossref]

15. Attaran S, Moscarelli M, Athanasiou T, Anderson J (2013) Is coronary artery bypass grafting an acceptable alternative to myotomy for the treatment of myocardial bridging? Interact Cardiovasc Thorac Surg 2013; 16: 347-349. [Crossref]

16. Vales L, Kanei Y, Fox J (2010) Coronary artery occlusion and myocardial infarction caused by vasospasm within a myocardial bridge. J Invasive Cardiol 22: E67-E69. [Crossref]

17. Agirbasli M, Martin GS, Stout JB, Jennings HS 3rd, Lea JW 4th, et al. (1997) Myocardial bridge as a cause of thrombus formation and myocardial infarction in a young athlete. Clin Cardiol 20: 1032-1036. [Crossref]
18. Corrado D, Pelliccia A, Bjørnstad HH, Vanhees L, Biffi A, et al. (2005) Cardiovascular pre-participation screening of young competitive athletes for prevention of sudden death: proposal for a common European protocol. Consensus Statement of the Study Group of Sport Cardiology of the Working Group of Cardiac Rehabilitation and Exercise Physiology and the Working Group of Myocardial and Pericardial Diseases of the European Society of Cardiology. Eur Heart J 26: 516-524. [Crossref]

19. Corrado D, Pelliccia A, Heidbuchel H, Sharma S, Link M, et al. (2010) Recommendations for interpretation of 12-lead electrocardiogram in the athlete. Eur Heart J 31: 243-259. [Crossref]

20. Josephson RA, Shefrin E, Lakatta EG, Brant LJ, Fleg JL (1990) Can serial exercise testing improve the prediction of coronary events in asymptomatic individuals? Circulation 81: 20-24. [Crossref]

21. (1985) Multiple Risk Factor Intervention Research Group. Exercise electrocardiogram and coronary heart disease mortality in the multiple risk factor intervention trial. $\mathrm{Am} \mathrm{J}$ Cardiol 55: 16-23. [Crossref]

22. Maron BJ, Thompson PD, Ackerman MJ, Balady G, Berger S, et al. (2007) Recommendations and Considerations Related to Preparticipation Screening for Cardiovascular Abnormalities in Competitive Athletes: 2007 Update A Scientific Statement From the American Heart Association Council on Nutrition, Physical Activity, and Metabolism. Circulation 115: 1643-1655. [Crossref]

23. Frame PS (1986) A critical rewiew of adult health maintenance. I. Prevention of atherosclerotic diseases. J Fam Pract 22: 341-346. [Crossref]

24. Katzel LI, Fleg JL, Busby-Whitehead MJ, Sorkin JD, Becker LC, et al. (1998) Exercise-induced silent myocardial ischemia in master athletes. Am J Cardiol 81: 261265. [Crossref]

25. Jensen-Urstad K, Bouvier F, Saltin B, Jensen-Urstad M (1998) High prevalence of arrhythmias in elderly male athletes with a lifelong history of regular strenuous exercise. Heart 79: 161-164. [Crossref]

26. Hood S, Northcote RJ (1999) Cardiac assessment of veteran endurance athletes: a 12 year follow up study. Br J Sports Med 33: 239-243. [Crossref]

27. COCIS (2009) Protocollicardiologici per ilgiudizio di idoneita`allo sport agonistico. Rome: Casa Editrice. Scientifica Internazionale 1-188.

28. Ermolao A, Roman F, Gasperetti A, Varnier M, Bergamin M, et al. (2015) Coronary CT angiography in asymptomatic middle-aged athletes with ST segment anomalies during maximal exercise test. Scand J Med Sci Sports. [Crossref]

29. Biffi A, Delise P, Zeppilli P, Giada F, Pelliccia A, et al. (2013) Italian Society of Sports Cardiology and Italian Sports Medicine Federation. Italian cardiological guidelines for sports eligibility in athletes with heart disease: part 2. J Cardiovasc Med (Hagerstown) 14: 500-515. [Crossref]

Copyright: (C2015 Bolognesi M. This is an open-access article distributed under the terms of the Creative Commons Attribution License, which permits unrestricted use, distribution, and reproduction in any medium, provided the original author and source are credited. 